\title{
Thermal distortion analysis method for TMCP steel structures using shell element
}

\author{
Yunsok Ha, and Rajesh S.R.
}

\author{
Samsung Heavy Industries Co., LTD, 530 Janpyeong-Dong, Geoje, 656-710, South Korea
}

\begin{abstract}
As ships become larger, thicker and higher tensile steel plate are used in shipyard. Though special chemical compositions are required for high-tensile steels, recently they are made by the TMCP (Thermo-Mechanical control process) methodology. The increased Yield / Tensile strength of TMCP steels compared to the normalized steel of same composition are induced by suppressing the formation of Ferrite and Pearlite in favor of strong and tough Bainite while being transformed from Austenite. But this Bainite phase could be vanished by another additional thermal cycle like welding and heating. As thermal deformations are deeply related by yield stress of material, the study for prediction of plate deformation by heating should reflect the principle of TMCP steels. The present study is related to the development of an algorithm which could calculate inherent strain. In this algorithm, not only the mechanical principles of thermal deformations, but also the initial portion of Bainite is considered when calculating inherent strain. Distortion analysis results by these values showed good agreements with experimental results for normalized steels and TMCP steels during welding and heating. This algorithm has also been used to create an inherent strain database of steels in Class rule.
\end{abstract}

KEY WORDS: TMCP steel; Thermal distortion analysis; Inherent strain; Finite element method; Shell element.

\section{NOMENCLATURE}

$\varepsilon^{\text {th }}:$ thermal strain

$\varepsilon^{\mathrm{pl}}:$ plastic strain

$\varepsilon^{\mathrm{ph}}:$ phase transformation strain

$\varepsilon^{\mathrm{el}}:$ elastic strain

$\varepsilon^{*}:$ inherent strain

$\mathrm{k}_{1}:$ stiffness of restrained zone

$\mathrm{k}_{2}$ : stiffness of heated zone

$\mathrm{E}$ : elastic modulus of restrained zone (GPa)

$\sigma_{\mathrm{T}}:$ tensile stress $(\mathrm{MPa})$

$\sigma_{\mathrm{Y}}:$ yield stress $(\mathrm{MPa})$

E.L. : elongation

$\mathrm{D}$ : average diameter of grain size $(\mathrm{mm})$

Ms : martensite start temperature $\left({ }^{\circ} \mathrm{C}\right)$

Mf : martensite end temperature $\left({ }^{\circ} \mathrm{C}\right)$

$\mathrm{N}$ : austenitic grain-size (ASTM number)

Bs : bainite start point $\left({ }^{\circ} \mathrm{C}\right)$

$\mathrm{T}_{\mathrm{G}}$ : grain-size coarsening temperature $\left({ }^{\circ} \mathrm{C}\right)$

$\mathrm{T}_{\mathrm{R}}$ : room temperature $\left({ }^{\circ} \mathrm{C}\right)$

$\mathrm{X}_{\mathrm{F}}$ : ferrite portion

$\mathrm{X}_{\mathrm{A}}$ : austenite portion

$\mathrm{X}_{\mathrm{B}}$ : bainite portion

$\mathrm{X}_{\mathrm{M}}$ : martensite portion

Corresponding author: Ha. Yunsok

e-mail:yunsok@samsung.com

\section{INTRODUCTION}

Recently, very fast enhancement has been observed in the thermal deformation theory and analysis technique of large shell structures. The use of shell element, and strains from pre-calculation as boundary conditions are the main features of these technique. Several researches were done by Jung et al. (2007) using averaged eigen-value plastic strains, and by Ha et al. (2007) with inherent strains containing phase transformation and hardening. The common target of these researches is to get final deformations of a welded structure by using strain calculation results as boundary condition in elastic analysis. The well-known elastic analyses using straininput are traditional equivalent forces method (Ha et al., 2006) and SDB method (Ha, 2007) whose merits are easy handling of curved welding line and exact stress field.

In naval architecture, welding and fabrications by heating are essential processes. But these processes are good examples for thermal distortions of structures. Therefore, the better reliability of thermal distortion analysis means the better controllability of welding structure by inverse design (Fig. 1) or pre-bending in advance. Although thermal distortion analysis will be revised in its accuracy, if the difference in experimental results of welding distortion are over $10 \%$, which leads to another problem that need proper consideration. Local volatility of final yield stress components of steel must be comparable to those in mill certificate. Though recent inherent strain theory already uses 
yield stress which reflects chemical and physical information given in mill certificate, a steelmaking method is still not related to inherent strain calculation.

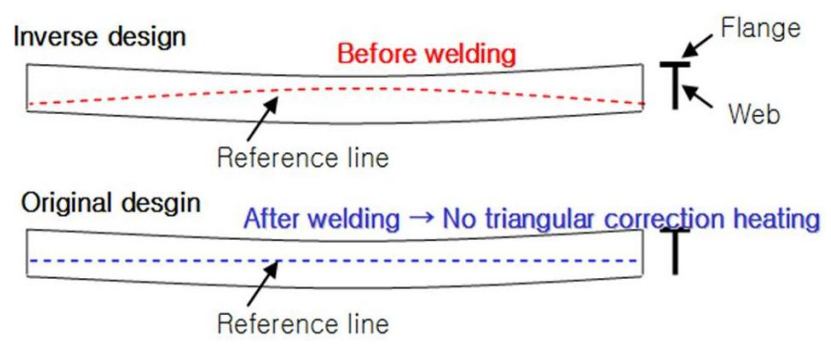

Fig. 1 An example of inverse design.

The mechanical properties of steel can be quite different even in same grade of steel due to minute variation that occur in same type of steel making process. Especially, as ships become larger and operated in low temperature environment, steels are made by TMCP (Thermo-Mechanical Control Process) skill in order to obtain a high strength and low temperature properties. By the way, TMCP steels are known as a poor hot working type (Shin et al., 2007) (Fig.2). This paper describes a clear correlation between workability of TMCP steels in hot bending and their material properties. Also, advanced prediction method of thermal distortion for TMCP steel structures is developed by using shell-element based FEM.

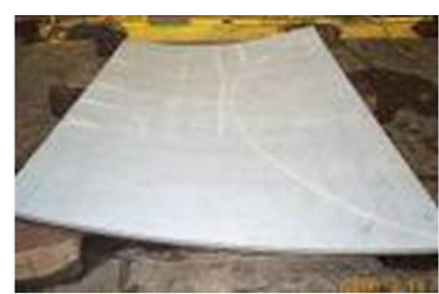

(a) Normalize

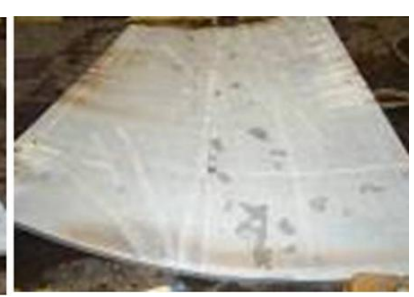

(b) TMCP
Fig. 2 Density of heating lines for hot forming (Shin et al., 2007) (to same target surface).

\section{TMCP Steel}

Steels have various properties according to their chemical composition. Even a very small variation of a chemical element can affect their mechanical properties. Especially, slight variation in the amount of Carbon, Manganese, Silicon, Copper and Molybdenum changes its yield stress. High strength TMCP steel plate could be developed without the larger addition of these alloying elements. TMCP manufacturing process is related to the phase transformation. The final phase of TMCP steels contains Bainite portion as the cooling rate is accelerated in steelmaking process (Fig. 3). Most normalized steel in Class rule before heating mainly consists of ferrite and pearlite. On the contrary, TMCP steel has Bainite phase from austenite in cooling phase. Bainite has about $500 \mathrm{MPa}$ yield strength (SYSWORLD, 2006) which is more than ferrite (but less than martensite). Accordingly, TMCP steels gain a high strength by phase transformation, instead of using chemical elements of high cost (SNAK, 2006).

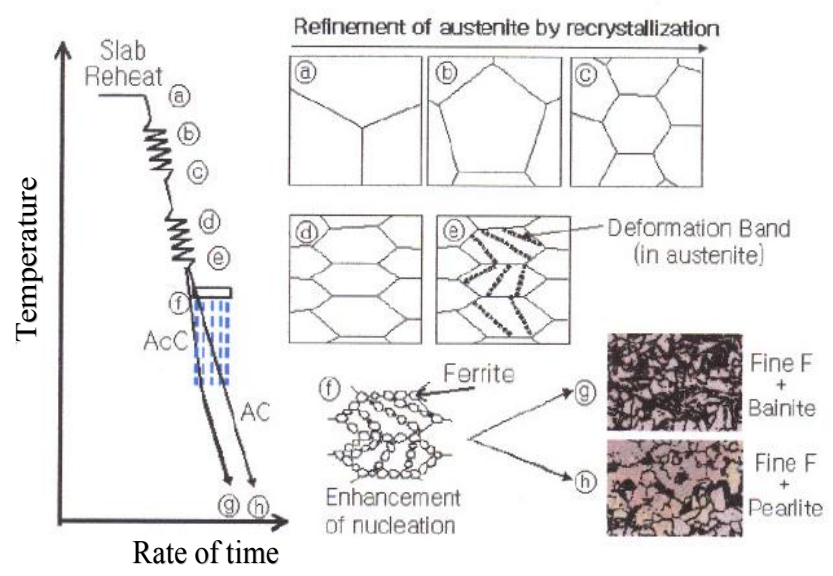

Fig. 3 Schematic CCTD of TMCP steel.

TMCP steels have been used in the ship structures under the approval of ship classification societies. But they have problems in distortion analysis of local heating zone. If the base metal recovers the austenite by heating at a temperature over melting point, the amount of Bainite will be changed due to the variation in cooling rate with its steelmaking process. The portion of Bainite may decrease during welding because of the air (slower than steelmaking process) cooling. On the other hand, it will increase in line heating owing to the water cooling (but still has lower yield strength than same grade normalized steel). The inherent strain formula for that mechanism is already known and a new similar formula for Bainite could be developed. In the air cooling, if we use the previous algorithm at TMCP steels, we will overestimate thermal deformation value.

\section{Inherent Strain}

The inherent strain is unrecoverable strain after elastic loads are removed from the structures and can be defined as Equation (1) (Jang et al., 1997). Normally, HAZ (heat affected zone) have tensional stress and compressive strain. So if stress-strain curve is drawn for HAZ, it would be as in Fig. 4.

$\varepsilon^{*}=\varepsilon^{t h}+\varepsilon^{p l}+\varepsilon^{p h}=\varepsilon^{\text {total }}-\varepsilon^{e l}$ 
Though thermal strain (containing phase strain) want to pull this curve to left direction as its value, stiffness of adjacent region will not let go on and will make plastic strain. Inherent strain is the starting point of stress-strain curve as shown in Fig. 4.

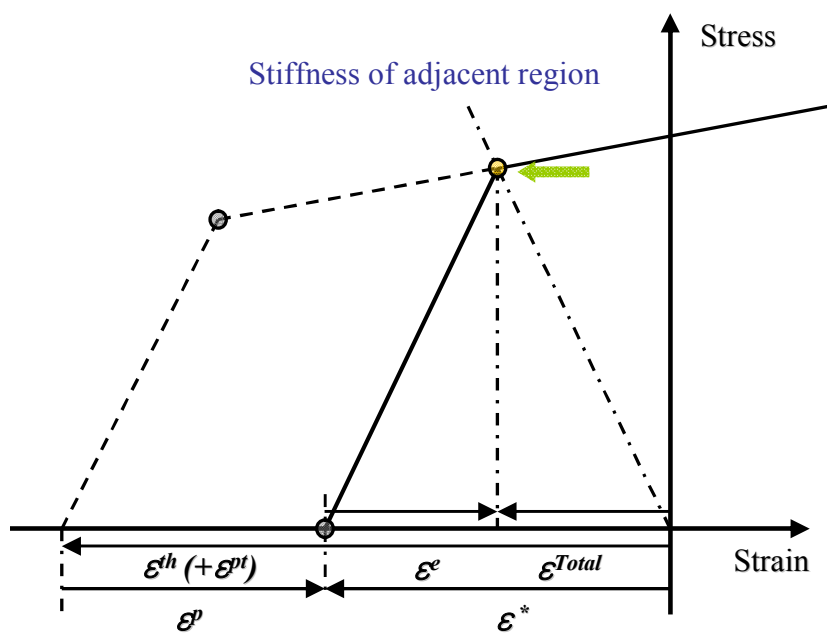

Fig. 4 Stress-strain relation after thermal cycle.

In 2D problems, the final form of Equation (1) can be written as Equation (2) (Ha et al., 2007). This equation reflects the phase transformation in two categories. Firstly, it is possible to consider the volume expansion through the Martensite phase transformation by modifying thermal expansion coefficient (Ha et al., 2006). And secondly, material properties in HAZ (heat affected zone) are given a weight for portion with each phase. For example, high thermal expansion coefficient by residual austenite of stainless steel, and high yield stress by Martensite of rapidly cooled steel can be considered by Equation (2).

$$
\varepsilon^{*}=\frac{-\sigma_{Y}+H \cdot \int \alpha^{\bmod } d T}{E+H \cdot\left(\frac{k_{1}}{k_{2}}+1\right)}\left(\frac{k_{1}}{k_{2}}+1\right)
$$

where

$$
\begin{aligned}
& \int \alpha^{\mathrm{mod}} d T=\varepsilon^{t h}+\varepsilon^{p t} \\
& H=\frac{E \cdot E_{t}}{E-E_{t}} \\
& E_{t}=\frac{\sigma_{T}-\sigma_{Y}}{E . L .}
\end{aligned}
$$

Water (fast) cooling is used in line heating, and it creates various phases in the HAZ. Therefore, inherent strain containing phase transformation is very useful analysis tool for deformation predictions of line heating. This part is an important issue in this paper, and the inherent strain for TMCP steel including bainite as well as existing 3 phases such as ferrite, austenite, and martensite (the last phase from austenite) is being calculated.

\section{AN ALGORITHM FOR FINAL PORTION OF PHASE}

There are several equations for estimating final portion of phase according to cooling speed. The trustworthy ones among known results are $0 \%, 50 \%, 100 \%$ guarantee velocity for martensite and bainite (Atkins, 1980). In this study, final portions of each phase are calculated by interpolations for the cooling speed (Fig. 5) obtained from FEM heat transfer analysis.

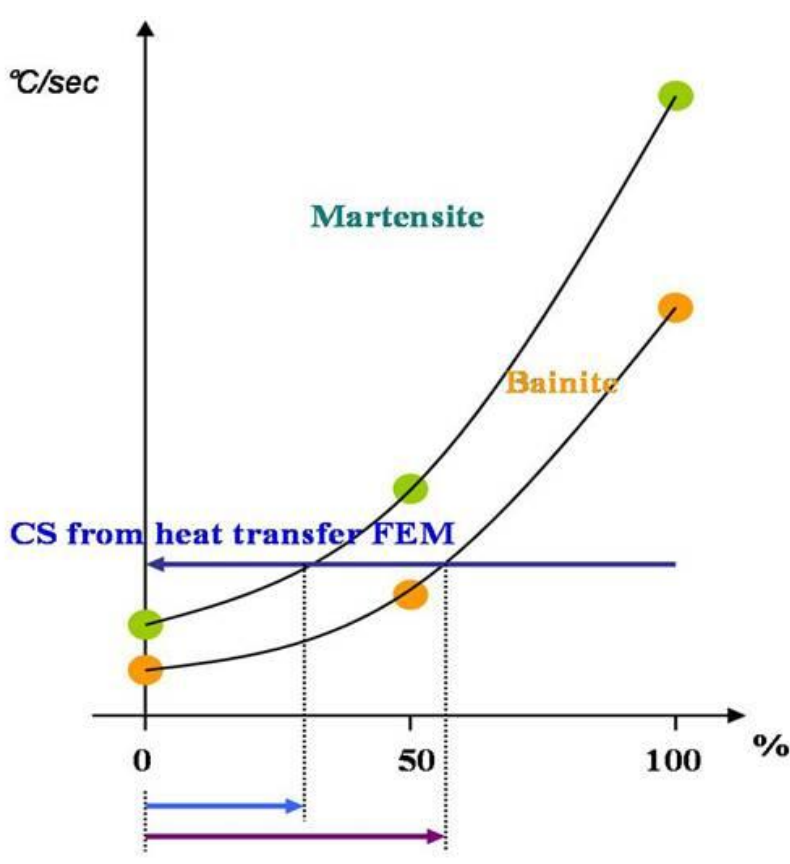

Fig. 5 Estimation of final phase portion.

The Martensite-end temperature is greater than room temperature in mild steel as Equation (3). Therefore, portions of each phase are expressed based on temperaturedependency. The phase transformation temperature is not linear to temperature, but occurs rapidly at the start point. So, an exponential term (Avrami, 1939) is used for conventional study for phase transformation from austenite. As the exponential functions have an asymptotic line, the end of the phase transformation is represented as $1 \%$ of parent phase (Equation (4)). 


$$
\begin{aligned}
M s= & 512-453 \mathrm{C}-16.9 \mathrm{Ni}+15 \mathrm{Cr}-9.5 \mathrm{Mo} \\
& +217(\mathrm{C})^{2}-71.5(\mathrm{C})(\mathrm{Mn})-67.6(\mathrm{C})(\mathrm{Cr}) \\
& -11.1 \mathrm{Si}\left({ }^{\circ} \mathrm{C}\right) \\
M f= & M s-215\left({ }^{\circ} \mathrm{C}\right) \\
B s= & 830-270 \mathrm{C}-90 \mathrm{Mn}-37 \mathrm{Ni}-70 \mathrm{Cr}-83 \mathrm{Mo}
\end{aligned}
$$$$
k_{M}=\frac{\ln 0.01}{M s-M f}
$$$$
k_{B}=\frac{\ln X_{M}\left(T_{R}\right)-\ln X_{B+M}\left(T_{R}\right)}{B s-M s}
$$$$
X_{F}(T)=1-X_{M+B}\left(T_{R}\right)
$$$$
X_{A}(T)=
$$$$
\begin{cases}\left(1-X_{F}(T)\right) \cdot e^{k_{B} \cdot M a x[(B s-T), 0]} & (T \geq M s) \\ \left(1-X_{F}(T)-X_{B}(T)\right) \cdot e^{k_{M} \cdot M a x[(M s-T), 0]} & (T<M s)\end{cases}
$$$$
X_{B}(T)=
$$$$
\begin{cases}\left(1-X_{F}(T)\right) \cdot\left(1-e^{k_{B} \cdot \operatorname{Max}[(B s-T), 0]}\right) & (T \geq M s) \\ \left(1-X_{F}(T)\right) \cdot\left(1-e^{k_{B} \cdot M a x[(B s-M s), 0]}\right) & (T<M s)\end{cases}
$$$$
X_{M}(T)=\left(1-X_{F}(T)-X_{B}(T)\right) \cdot\left(1-e^{k_{M} \cdot \operatorname{Max}[(M s-T), 0]}\right)
$$$$
X_{F}(T)+X_{A}(T)+X_{B}(T)+X_{M}(T)=1
$$

Equation (5) represents the temperature-dependent functions of each phase portion. Because Bainite is not a finally transformed one and depends on generation of Martensite, the portions of (residual) Austenite and Bainite are dependent on Martensite-start temperature (Ms) (Equation (3)). Also, Equation (5) includes an assumption that the mild steel has no residual austenite at room temperature as the carbon content is less than $0.2 \%$ (Marder and Krauss, 1967). Finally, these equations can be expanded as weight function as in Equation (6).

$$
f(T)=\sum_{i}^{F, A, B, M} X_{i}(T) \cdot f_{i}(T)
$$

\section{THE ESTIMATION OF YIELD STRESS}

Now, the yield stress of the HAZ of TMCP steel will no longer be calculated using Y.P. number obtained from mill certificate. As the chemical composition of the TMCP steel is lower than normalized steel, the calculated yield stress of TMCP should be lower. In this study, Equations (7) (KiharaSuzuki-Tamura's formulae) have been used (Masubuchi, 1980) not only for the calculation of tensile stress and elongation, but also for calculating inherent strain containing plastic hardening (Equation (2)).

$$
\begin{aligned}
& C_{y}=C+\frac{M n}{5}+\frac{S i}{7}+\frac{C u}{7}+\frac{N i}{20}+\frac{M o}{2}+\frac{V}{0.9} \\
& \left(+\frac{V}{a_{V}}+\frac{N b}{a_{N b}}+\frac{A l-A l_{\text {killed }}}{a_{A l}}+\frac{N}{a_{N}}\right) \\
& C_{t}=C+\frac{M n}{5}+\frac{S i}{7}+\frac{C u}{7}+\frac{N i}{20}+\frac{C r}{9}+\frac{M o}{2}+\frac{V}{2} \\
& C_{e}=C+\frac{M n}{9}+\frac{S i}{12}+\frac{C u}{10}+\frac{N i}{20}+\frac{C r}{4}+\frac{M o}{2.5}+\frac{V}{1.25} \\
& \sigma_{Y}=373.8 C_{y}+167.3 \\
& \sigma_{T}=609 C_{t}+241.5 \\
& \text { E.L. }=0.495-0.512 C_{e}
\end{aligned}
$$

Equations (7) consist of alloying element that was included in the earlier stages of steel making. Presently new alloying elements are added to steel making process and it will affect its strength value. In this paper, these elements are divided into two groups. The first group consists of element that makes fine-grained steel for strength. For example, Vanadium (V), Titanium (Ti), Niobium (Nb), and remained aluminum from killed steel.

Other group consists of alloying element like Nitrogen (N) in $\mathrm{F}$ grade steel (working temperature: $-60{ }^{\circ} \mathrm{C}$ ). This nitrogen content improves the toughness at negative temperatures. This effect can prevent moving of the dislocation, so that the suppressed plastic deformation makes the yield point to arise. For F-grade steel, the carbon content is lower compared to other normalized ones. So, if nitrogen is not included in the equation, the calculated deformation value will be low, Thus Equation 7 has benefit, when Nitrogen term is included.

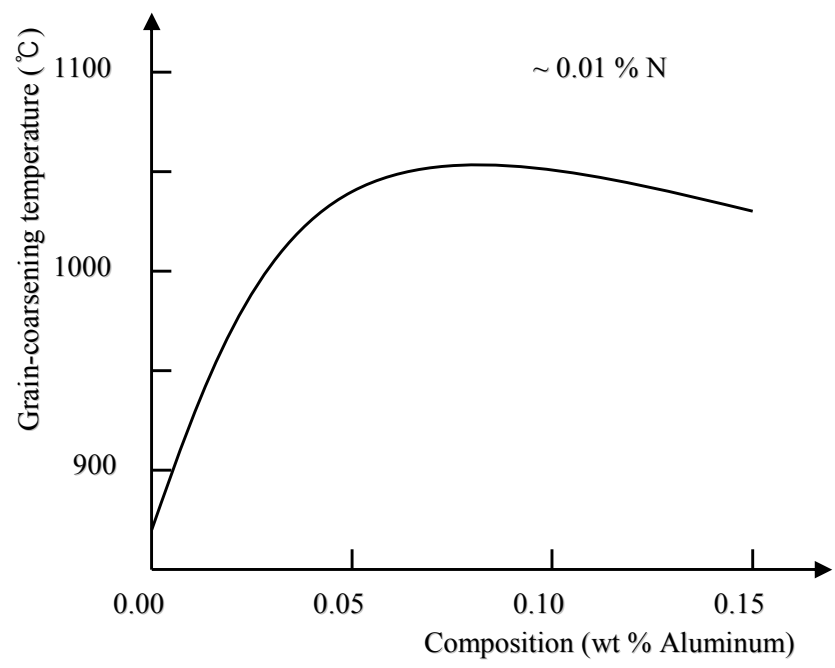

Fig. 6 Grain-coarsening temperature. 
During hot working of F-grade steel, the nitrogen reacts with aluminum, which lowers the austenite grain coarsening temperature (Fig. 6) (Gladman, 1963). This will affect its ASTM number (Fig. 7) (ASTM, 1963), the change in ASTM number will affect average diameter of grain size, and the diameter will affect martensite yield strength which is related to Equation (8).

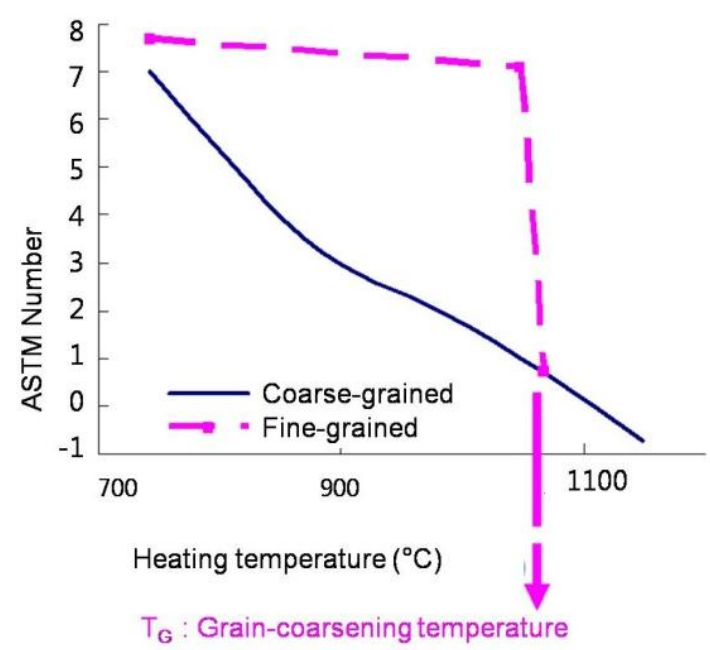

Fig. 7 Austenitic grain size (ASTM number).

Finally this martensite yield strength variation will have an effect on the inherent strain. As nitrogen content is considered, the inherent strain calculation process has been revised based on Equation (9).

$$
\begin{aligned}
\sigma_{Y}= & \left(370+\frac{27.1}{\sqrt{D}}\right)+(480-370) \times \frac{\sqrt{C}}{\sqrt{0.2}} \\
& +\frac{\sqrt{C}}{\sqrt{0.2}} \times \frac{48.0-27.1}{\sqrt{D}}(M p a) \\
D & =0.359 e^{-0.346 N}
\end{aligned}
$$

(for fine-grained steel)

$$
\begin{aligned}
N & = \begin{cases}-0.002 \times T_{\text {Max }}+9.2 & \left(T_{\text {Max }}<T_{G}\right) \\
\operatorname{Max}\left[0.5,-\frac{T_{M a x}}{55}+20\right] & \left(T_{\text {Max }}>T_{G}\right)\end{cases} \\
T_{G} & =\min [1050,4000 \times A l+850]
\end{aligned}
$$

In API steel, a mark ' $2 \mathrm{~W}$ ' means TMCP. There are several mill certificates of 'API $2 \mathrm{~W} 50$ ' based on their thickness. After calculation of yield stress under thermal cycle it could be observed that, the values are lower and more even than those written on mill certificates as shown in Fig. 8. The thinner the plate, the wider the difference of yield stress before (in mill certificate) and after thermal cycle. It means that 'TMCP' effect is excellent for thin plate. So, if the yield stress in mill certificate is used for the calculation of inherent strain and thermal distortion analysis, then the deformation results of TMCP steel structure are overestimated.

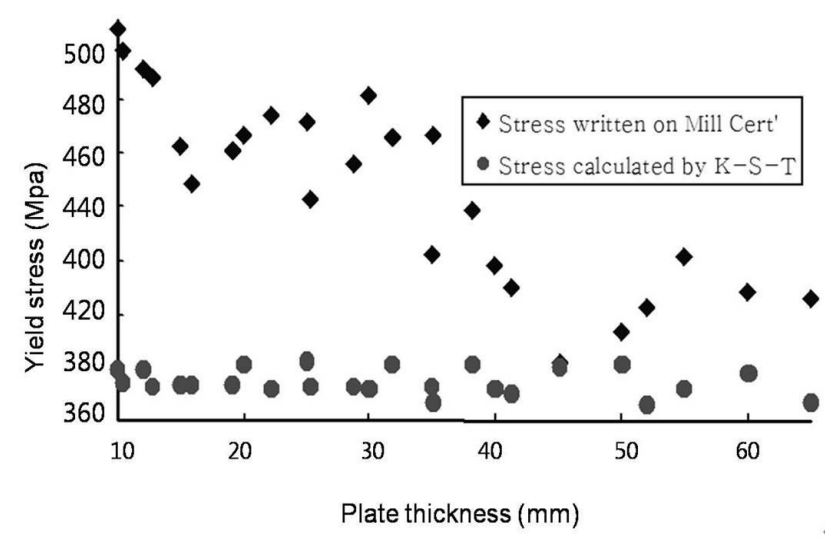

Fig. 8 Yield stress calculation results following KiharaSuzuki-Tamura's formulae.

\section{INHERENT STRAIN TABLE}

Table 1 is an example of calculated inherent strain

\begin{tabular}{|c|c|c|c|c|}
\hline & & & \multicolumn{2}{|c|}{ Cooling rate $\left({ }^{\circ} \mathrm{C} / \mathrm{s}\right)$} \\
\hline & & & 10 & 100 \\
\hline \multirow{4}{*}{$\mathrm{AH}$} & \multirow{2}{*}{32} & Normalized & -0.00681 & -0.00832 \\
\hline & & TMCP & -0.00630 & -0.00771 \\
\hline & \multirow{2}{*}{36} & Normalized & -0.00774 & -0.00904 \\
\hline & & TMCP & -0.00663 & -0.00787 \\
\hline \multirow{4}{*}{$\mathrm{DH}$} & \multirow{2}{*}{32} & Normalized & -0.00687 & -0.00841 \\
\hline & & TMCP & -0.00634 & -0.00782 \\
\hline & \multirow{2}{*}{36} & Normalized & -0.00776 & -0.00907 \\
\hline & & TMCP & -0.00666 & -0.00791 \\
\hline \multirow{4}{*}{$\mathrm{EH}$} & \multirow{2}{*}{32} & Normalized & -0.00690 & -0.00845 \\
\hline & & TMCP & -0.00638 & -0.00787 \\
\hline & \multirow{2}{*}{36} & Normalized & -0.00777 & -0.00910 \\
\hline & & TMCP & -0.00669 & -0.00795 \\
\hline \multirow{4}{*}{$\mathrm{FH}$} & \multirow{2}{*}{36} & Normalized & -0.00826 & -0.00957 \\
\hline & & TMCP & -0.00762 & -0.00913 \\
\hline & \multirow{2}{*}{40} & Normalized & -0.00916 & -0.01023 \\
\hline & & TMCP & -0.00785 & -0.00931 \\
\hline
\end{tabular}
(Equation (2)) from yield stress under assumed cooling rate $\left(10 \sim 100^{\circ} \mathrm{C} / \mathrm{s}\right)$ and disk-spring restraint (Jang et al., 1997) used in line heating.

Table 1 Inherent Strain About Class Rule. 
The difference of inherent strain between normalized steel and TMCP steel is large for high tensile strength steel. This means that higher level of cooling effort was carried out for higher grade steel plates.

Alphabetical order of steel plate names is related to the test temperature. The ' $A$ ' grade means that its test is about $20{ }^{\circ} \mathrm{C}$ and moving down the table, test temperature condition decreases. The difference of inherent strain is small for $\mathrm{F}$ grade (test temperature : $-60{ }^{\circ} \mathrm{C}$ ) steel. For $\mathrm{F}$ grade steel, the nitrogen has contribution to its strength as an alternation to carbon. The difference in carbon content of normalized Fgrade steel and its TMCP is smaller than other grades.

Inherent strain values are linear to deformation of structure at elastic analysis. So, the relative deformation of cases can be estimated from the Table 1 .

\section{APPLICATION}

Fig. 9 shows a PDA program for obtaining welding deformation on fillet or T-butt weld structure. This program has menu to choose TMCP steels. It makes the solution higher and more accurate than any other algorithm. Provided that the pre-reverse deformation system to prevent rework following thermal distortion is introduced, this study will can have a great roll on accurate prediction.

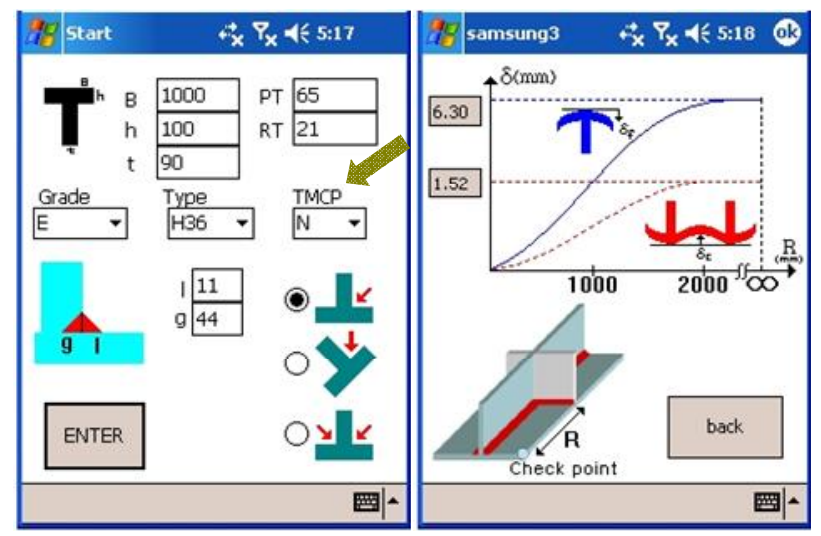

Fig. 9 PDA Programming of welding deformation considering TMCP steel.

\section{CONCLUSIONS}

In this study, the connectivity between the TMCP steelmaking process and the yield stress of steel plate after the thermal cycles including heating and welding have been discussed clearly. The Bainite phase has been added to algorithm for obtaining inherent strain using continuous cooling transformation diagram.
Traditional formulae for estimating steel strength are expanded by dealing with more chemical components. Using these algorithms, an application $\mathrm{S} / \mathrm{W}$ for evaluating thermal distortion containing TMCP steel has been developed.

\section{REFERENCES}

Jung, G.H. Huang, T.D. Dong, P. Dull, R.M. Conrardy, C.C. and Porter, N.C., 2007. Numerical prediction of buckling in ship panel structure. Journal of Ship Production, 23 (3), pp.171-179.

Ha, Y.S. Jang, C.D. Kim, J.T. and Mun, H.S., 2007. Analysis of post-weld deformation at the heat-affected zone using external forces based on the inherent strain. International Journal of Precision Engineering and Manufacturing, 8(4), pp. 56-62.

Ha, Y.S. and Jang, C.D., 2006. An improved inherent strain analysis for plate bending by line heating considering phase transformation of steel. International Journal of Offshore and Polar Engineering, 17(2), pp. 139-144.

Ha, Y.S., 2007. Development of welding distortion analysis method using residual strain as boundary condition. Samsung Journal of Innovative Technology, 3(1), pp. 173-180.

Shin, S.B. Kim, H.G. Kim, K.G. and Yoon, J.G., 2007. A study on the factors affecting the workability of TMCP steel for curved hull plate. In: International Welding and Joining Conference-Korea. Seoul, Korea, 10-12 May 2007.

SYSWORLD® 2006. Release notes, ESI Group, 39.

SNAK, 2006. Literature survey for the further use of TMCP steel in shipbuilding industries, pp. 3-4.

Jang, C.D. Ko, D.E. and Seo, S.I., 1997. A study on the prediction of deformation of plates due to line heating using a simplified thermal elasto-plastic analysis. Journal of Ship Production, 13(1), pp. 22-27.

Atkins, M., 1980. Atlas of continuous cooling transformation diagrams for engineering steels. American Society for Metals, British Steel Corp. (Metals Park, Ohio, Sheffield, Eng), pp. 228-229.

Avrami, M., 1939. Kinetics of phase change. I General theory. Journal of Chemical Physics, 7(12), 1103-1112.

Marder, A.R. and Krauss, G., 1967. The morphology of martensite in iron-carbon alloys. Trans. ASM, 60, pp. 651-660.

Masubuchi, K., 1980. Analysis of welded structures. Oxford, UK: Pergamon Press, pp. 378-380.

Gladman,T., 1963. Metallurgical developments in Carbon steels. Special report 81, The Iron and Steel Institute, London, pp. 68-70.

ASTM, 1963, Estimating the average grain size of metals. American Society for Testing and Materials Designation, pp. 112-163. 